\title{
Whence God?
}

Defining religion has never been simple; it is not a one-dimensional, monolithic condition but rather a complex enterprise with multi-dimensional consequences (Saroglou, 2013). Clifford Geertz (1973) characterized religion as a cultural form which "denotes an historically transmitted pattern of meanings embodied in symbols, a system of inherited conceptions expressed in symbolic forms by means of which [humans] communicate, perpetuate, and develop their knowledge about and attitudes about life (p. 89).” Though oft cited (e.g., Bellah, 2011), and though it is clearly applicable to religion, certainly this definition could be used to describe other aspects of culture as well—art, literature, even journalistic traditions.

When it comes to religion, therefore, nothing is simple or straightforward. It is thus possible for Boyer (2010) to argue the concept into oblivion by simply demonstrating the uncertainty and ambiguity of every major attribute Geertz, or anyone else, might ascribe to religion. Nonetheless, though Boyer's points evoke needed caution, he himself acknowledges that the presence of religion in the real world cannot be dispensed with so easily. Religion, whether you are for it or against it, is a central part of global human culture. It cannot be ignored or finessed, it must be understood.

Recently, Riesebrodt (2010) argued that religion should be defined relative to its three historically primary concerns. These are helping people to 1) survive misfortune, 2) handle crises, and 3) receive salvation. He further argued that if we want to understand religion we must examine it relative to its liturgies, that is, in terms of its institutionalized habitus (Bourdieu, 1977). These liturgies are encoded versions of religious actions/rituals which are considered appropriate for addressing misfortunes, crises, and the pursuit of salvation. In order to explain religion, however, and this point is of central relevance to the present work, Riesebrodt argued 
that we must see that human beings perform these symbolic rituals, i.e., liturgies, in order to invoke the action of the higher power relative to one of the three core concerns-misfortune, crisis, and salvation.

Riesebrodt's perspective applies primarily to mature religions, i.e., those possessing stable liturgies. It is thus not a theory of the origin of religion, per se. However, if we consider religion in light of Riesebrodt's perspective, it is clear that its origin must relate to the issue of salvation. There is nothing uniquely religious about handling crises or misfortunes; even animals recognize and respond to these. And there is no reason to think that humans would suddenly develop and invoke higher powers in dealing with crises and misfortunes when there would already be adaptive behaviors in place for handling those circumstances. In other words, there is no necessity for humans to think beyond the contingencies of the physical world as they seek to handle such conditions.

The issue of salvation, however, grows out of a qualitatively different relation to the world. In order to even conceive of salvation, in any form, humans must be capable of comprehending the concept of transcendence. That is, they must conceive of states and circumstances that are beyond the states and circumstances of their normal existence. And the fact is, these cannot be understood other than by reference, either directly or indirectly, to some notion of a higher power.

This indicates two things. First, it would seem to mean that the origin of religion must largely reflect higher-level symbolic processes. In other words, the evolution of a concern for salvation must necessarily precede the application of the conception of a higher power to the "lower-level" concerns of handling crises and misfortunes. The second point is consistent with this and of central importance. It is that if we wish to understand the origin of religion as 
Riesebrodt characterizes it, then we must first explain the evolution of human being's conception of a higher power.

Considering the problem in this manner raises a very interesting and easily overlooked issue. That is that, without question, having a conception of a higher power is a true universal characteristic of human beings. Everyone, regardless of cultural sophistication (Bellah, 2011), regardless of whether they believe or don't believe (Dumitriu, 1982), approve or disapprove (Hume, 1779/1989), nonetheless has some conception of a higher power. Children characteristically develop such notions beginning about age five (Fowler, 1981). And most interestingly, even in highly secularized countries, without any cultural or parental support, children will spontaneously begin to construct their own ritualistic conceptions of transcendent processes (Demmrich, 2013).

This universality of human's conceptions of higher powers is a critical fact and indicates at least two important points. First and most simply, such a conception cannot be difficult for the human brain to achieve. Despite the fact that the concept of a transcendent power is not only abstract but also without direct sensory support, our brains are perfectly capable and readily motivated to construct such an idea. Second, it would indicate that the origin of religion is not simply based on the evolution of a cognitive facility. In other words, the evolution of religion may be related to the conceptualization of higher powers, but this is not just a question of cognitive capabilities. That, it would seem, is actually the "easiest" part of the process. Rather, we must understand "higher power" not simply as an intellectual conception but as an indicant of emotional, motivational, interpersonal and social processes as well. 
Consequently, a complete understanding will entail the integration of ideas from a range of perspectives and disciplines. In what follows, we examine approaches to this problem from the domains of theology, sociology, psychology, and biology.

\section{The origin of ultimate meaning}

The notion of a higher power is a universal ideal. It need not, however, take on any particular content. It does not imply, per se, Allah, God, Yahweh, Brahman, Dharma, or any other particular conception. None the less, the notion of a higher power, just like religion itself, is not a simple, one-dimensional concept. This necessarily complicates its understanding. Each religion and spiritual tradition has its own perspective. In general, understandings of higher powers tend to characterize those powers either as beings, as principles, or as some combination of these two. The Christian God is usually conceived as a Divine Being, whereas the Buddhist Dharma is a Universal Principle. Many religions invoke both perspectives to some degree. For example, though all three aspects of the Christian Trinity are conceived as Beings, their overarching unity, the Godhead, is often seen as a Divine Principle.

However it is impossible to know whether the notion of a higher power first emerged as being, principle, or both. Thus we would like to find an approach that allows us to circumvent these complexities. Tillich's (1957) analysis of faith provides a straightforward and effective solution. Tillich defined faith as ultimate concern. From this perspective, one can only be ultimately concerned about that which is truly ultimate. For present purposes, therefore, that which receives ultimate concern can be understood as that which constitutes ultimate meaning within the experience of reality. Ultimate meaning may be a divine being, a universal principle, or something else. Whatever its specific manifestation, it constitutes a generalized formulation of what Riesebrodt terms a higher power. It is a transcendent force possessing ultimate existential 
meaning for people's lives. Therefore, in order to understand the origin of religion we must first explain how and why ultimate concern for ultimate meaning might initially have arisen within the human mind.

\section{Theological approaches}

Theological perspectives on this issue are generally of two sorts. One perspective is that an awareness of ultimate meaning is a gift from the transcendent power. Deist traditions generally view faith as a gift of God. By virtue of this gift of ultimate concern, therefore, mankind is able to directly contact the sacred. Another perspective, especially emphasized by non-deistic traditions, holds that ultimate meaning is immanent within all things, especially life, and has no beginning or end. Ultimate concern then would always be present within us, but would require the proper circumstances for its awakening.

These perspectives are certainly relevant and important to persons trying to gain some understanding, within one or more spiritual traditions, of life, existence, and their own "true nature." From a scientific standpoint, however, theological perspectives create issues, not solutions. The scientific approach need not be in opposition, however, to such perspectives. It is more the case that the theological perspective is independent of scientific concerns. Regardless of the truth-value of the theological views, if conceptions of ultimate meaning are consequential within the life of individuals and society, then considered scientifically, they must have a lawful manifestation in the material processes of human beings. In other words, in some manner they must exist in the person, in the brain, even in the body itself. They must also exist in the family, in the group, and in society at large. From a scientific point of view, therefore, evidence of the origin of the conception of ultimate meaning should be found in sociological, anthropological, psychological, and biological processes. 


\section{Sociological and anthropological approaches}

Some of the earliest perspectives concerning the origin of religion came from researchers working with traditional peoples of various regions. The work of Frazer (Pals, 1996) argued for a progressive growth in mankind's comprehension of the universe that began with primitive myth, progressed through religion, and, in his perspective, culminated in the rise of science. Such a view, however, is not only biased toward Western modes of thought, it is inadequate as a theory of origins. So-called primitive myths do not simply appear ex nihilo. Their existence presumes a view of the world that is already imbued with a sense of ultimate meaning.

A particularly influential perspective is due to the work of Emile Durkheim. For Durkheim (1912/1995), the sacred was coextensive with the tribe, that is, the fundamental social unit of which a person is a part. The totem represents the ultimate meaning of the tribe, its dynamic core. The sacred becomes apparent as the person joins completely with their social unit, both living and dead. In fact, all societies have importantly linked their spiritual existence with both their living community and their dead ancestors as well (Cassirer, 1944). Variations on Durkheim's scheme have been proposed by various persons, including Riesebrodt (2010).

Max Weber's work (Weber, 1922/1956) provided an important examination of how sociological forces maintain, transform, and utilize religious ideas and practices. His ideas, however, assumed the universality of religious thought. Hence, Weber provides an analysis of the evolution of religion, but strictly speaking, not its origin.

From the present perspective, this issue is endemic to the sociological perspective. Sociological processes are critical to the evolution of religions, but they cannot determine the origin of ultimate meaning. 
There are at least two reasons for this. First, the variability in patterns of religious practice, even within traditions, clearly indicates a bottom-up process. That is, variation begins with individuals. If the origin of religion was top-down, in other words, if the originating structure of religions came from society, there should be greater uniformity in religious forms both between and within traditions. Instead, I would argue that, in effect, each individual is always creating religion anew and thus social institutionalization is necessary for the stabilization of traditions.

The second problem with the sociological origin of ultimate meaning is that, simply and most importantly, on its own a sociological process cannot give meaning to the concept of a higher power. Meaning must arise within individuals. This is one basic difficulty with Bellah's recent characterization (Bellah, 2011). He attempts to characterize stages of religious meaning in relation to Merlin Donald's characterization of stages in the development of culture (Donald, 1991). As interesting as this approach might be, it is descriptive, not explanatory. It does not provide an account of how and why ultimate meaning first arises within the human mind.

\section{Psychological approaches}

Ideas begin ex vivo, in the experiences of individuals. They arise within the symbolic capabilities of the person and become manifest in the meaning of experience and in the structure and purpose of action. Their first appearance may be in a dream, a vision, a thought, or a feeling. From these subjective origins, however, ideas are broadcast into the social nexus, to live and grow, or to waste and die.

The origin of ultimate concern has been hypothesized to derive from a number of different psychological processes. One important approach examines the phenomenological nature of the experiences that provide the basis for the person's conception of ultimate meaning. 
Both Otto (1923) and Eliade (1959) argued that this method would reveal the uniqueness of the transcendent spiritual experience. This claim has not proved determinate, however. Some religious experiences do seem to be unique, but in general, spiritual or numinous experiences can be seen to be part of a spectrum of religiously relevant experiences (James, 1902/1985; Taves, 2009). The importance of this spectrum, though, cannot be ignored. Religions are founded, supported, and rejuvenated by such experiences.

Phenomenology alone, however, only goes so far. Emphasizing the phenomenology of religious experience tends to preclude further analysis. As several critics have noted, phenomenology tends to become theology rather than science. We need to understand the origins of these experiences as part of a whole process, one that is both cognitive and experiential (Lawson and McCauley, 1990).

One extreme perspective regards the source of these experiences as pathological. Some early psychological models, especially those of Freud (1961) and Marx (Pals, 1996), explained religion as a consequence of various psychological disorders. These views have been very influential. Freud argued that the higher power derived from the Father image and that religion consisted in a mass obsessive-compulsive disorder. For Marx, religion was supported by the bourgeois class as a way of opiating the proletariat against their thorough exploitation. Modern perspectives have also argued that a belief in a higher power derives from early childhood trauma (e.g., Abelow, 2009).

It is an unavoidable truth that religion and religious expression has been associated at various times in the past with a whole host and range of psychological disorders. It can be obsessive, manic-depressive, or schizophrenic; it can also be an escape, a means of avoiding reality. Nonetheless, these conditions cannot be the source of the conception of a higher power. 
A critical aspect of a person's symbolic engagement with their universe cannot be based on pathology. Pathological conditions do not support growth; they will destroy a species if they dominate. Evolution is never driven by pathology.

One straightforward reason religion can become a vehicle for behavioral pathology is because it can be intensely associated with all aspects of being human. In this regard it is similar to family, work, community, and so forth. All of these aspects of a full human life can be associated with the expression of various pathologies. There is nothing peculiar, in other words, about any pathology that would specifically link it to religion.

The antidote to pathology-based models might be taken to be the growing literature on the positive consequences of religion in a broad spectrum of life's circumstances (Reynolds and Tanner, 1983/1995; Ciarrocchi, 2012; Benson, Roehlkepartain and Scales, 2012). Religious involvement correlates with higher levels of well-being, happiness, life satisfaction, and lower levels of depression, illness, and suicide (see Paloutzian and Park, 2005; Park and Slattery, 2012).

It is important that religion produces material and psychological benefits for those who follow a religious tradition. These benefits are critical evidence of the success and value of each religion. Of greater importance from the standpoint of the present work, however, is that they confirm that evolutionary processes are relevant to the development of religion. This is because evolutionarily, only that which benefits the organism survives over time.

Nonetheless, though the physical and psychological benefits of religion might support a person's belief in a higher power, these benefits cannot explain the origin of that conception. The huge complex process of religion did not evolve simply to make people feel better, nor to optimize any specific wellness-based variable. These consequences, as stated above, would 
certainly support the survival of religious orientations, but they cannot be the primary reason for the origination of ultimate concern.

Jung (1938) saw religion as a symbolic expression of the growth of the psyche. Therefore the advent of a higher power symbolizes the evolution of a higher Self, one that is wellintegrated with respect to all aspects of its personality. Both traditionally and psychologically, the growth of self is an important aspect of the process of religion (Watts and Williams, 1988). Jung's perspective, however, is romantic. It envisions the growth of selfhood as if it were a quest. Clearly, such a view is imposed upon the process. Religion did not evolve to send Self on a quest, per se. The Jungian approach suffers from the same problem as the wellness perspectives. That is, the integrative wholeness of self might be a benefit of religion, but religion cannot have evolved for that purpose.

\section{Biological approaches}

Evolutionary psychologists such as Atran (2002) Lewis-Williams (2010), and others (see, Friedman, 2008), see the precursors of religion in certain basic psychological functions with evolutionary relevance. For example, one issue that has received a great deal of attention concerns "agency attribution." Agency attribution is where a person experiences a process or event as if it were the result of a choice by an intelligent agent. Suppose a person observed an event such as a rockslide. If they identified its cause as a loose rock or an earth tremor they would be making a physical attribution. If, however, they perceived the rockslide to be caused by an enemy or an "evil spirit," then they would be making an attribution of agency. Theorists would generally consider this to be a case of "overattribution." They then argue that, applying this perspective, agency attribution, and especially overattribution, might then be the evolutionary precursor to a conception of a higher power (Petrician and Burris, 2012). 
This approach, however, is faulty for several reasons. To begin with, as was discussed with respect to Freud and Marx, it essentially argues that religion evolved from, if not exactly a pathological condition, certainly an erroneous one. As was emphasized then, that is not consistent with the way evolution functions.

From a different vantage point, it can be pointed out that agency attribution, itself, is a characteristic of high survival value. Virtually all higher animals show some kind of agency attribution. In addition, it is most likely of greater survival value to over-attribute then underattribute agency in the world. Such overattribution, however, need not have anything to do with higher powers, at least not in a metaphysical sense. The point is that there is nothing special about agency attribution that makes it critical for an understanding of higher power.

A characteristic problem with most current evolutionary perspectives is that they fail to give sufficient consideration to the fact that virtually all aspects of higher cognition and affect are relevant to religious traditions. For example, Tweed (2006) has argued for a conception of religion as process, based on the critical importance of crossing and $d w e l l i n g$. His view is very interesting and is not explicitly evolutionary, but it can be used to make the point. Both processes, crossing and dwelling, find ample utilization in a variety of religious contexts, and both can be seen as evolved forms of basic animal behaviors, e.g., migration and nesting. Tweed's perspective is interesting in the present context because these are not behaviors that most people immediately associate with religion. Nonetheless, they are indicative of the wide range of high-level processes which are arguably relevant to the evolution of religion. Agency attribution, theory of mind, migration, meaning making, territoriality, kin and social processesindeed, all major, higher hominid-level cognitive and emotional processes have their role in the ongoing process of religion. They are all part of the habitus (Bourdieu, 1977) of religion. They 
are thus means; they are tools. They are not the source. They do not explain the origin of the higher power.

Neural theories of religion, or what Newburg (2010) calls neurotheologies, are in their infancy. They nonetheless represent an exciting and potentially important approach to understanding spiritual processes (Newberg and Waldman, 2009; McNamara, 2009).There are at least two serious difficulties with these approaches, however.

The first problem is that, until there exists an over-arching theory that provides a neural explanation of higher-order human behavior in general, there can be no currently meaningful explanation of such a complex and extensive process as religion. Religion, as has been emphasized many times, is not merely a faculty like object identification. It engages all of a person's faculties. Thus it is inconceivable that we could develop a neural theory of religion without a far greater understanding of how the brain operates in normal experience.

The second problem provides corroboration for the first. As continuing research is making more apparent, the neural processes, both neuroanatomically and neurochemically, that underlie religious experience and religious cognition are quite extensive (Newberg, 2012; Beauregard, 2012). But more importantly, they are not specific to religion. They are the same processes involved in virtually all other high-level human cognition, emotion, and social responsiveness. There would seem to be no area of the brain that is uniquely involved in religious experience. If this were true, then given our current level of understanding of the brain, neural process, per se, could not explain the evolution of religion.

An alternative to this view, however, is that our measuring instruments are not yet precise enough to distinguish a particular pathway. I argue this view with respect to my own perspective. However, the pathway I hypothesize to exist is of a particular sort. It is a differentiated system 
embedded wholly within the larger system responsible for daily, high-level symbolic processing. This would produce the findings Beauregard (2012) discusses. But a more sensitive future instrument should be able to discern the presence of such a system.

\section{A new perspective}

The remainder of this paper sketches an overview of a perspective which provides new insight into the nature and evolution of religious processing.

This perspective holds that the origin of ultimate meaning derives from two interacting processes. The first is symbolic consciousness, itself. The power of human beings' ability to generate and analyze symbolic systems is absolutely phenomenal. The human brain is capable of generating languages of languages (Doner, 2013a) concerning all things real and unreal. In

principle, it has no limits. Such a system is surely capable of generating a conception of a higher power. However, this fact reveals that something else is also needed. The conception must not just be generated, it must be valued.

Here we see the point of contact with the principle of self-interest. Valuing a higher power leverages against self-interest. This is the action of what Doner (2012) calls the true religion archetype, but which I now more generically refer to as the archetype of ultimate meaning (Doner, 2013b). It is hypothesized to be a neocortical system which modulates the ongoing activity of symbolic consciousness. This structure is capable of utilizing our symbolic construction of experience to create self-transcendent actions and experiences of the world, others, and oneself.

Given the criticisms of previous perspectives, however, two points must be clarified with respect to this archetype. First, it is best to conceive of the archetype of ultimate meaning as a differentiated pathway spanning several areas_-in fact, all the areas that research has identified 
as involved in religious processes (Newberg, 2012). Though it remains to be identified, it is important that the archetype has a neural instantiation. Quite conceivably, it has not been identified because of its complex nature and because current instruments are not technically advanced enough to do so.

Second, with respect to the evolution of the archetype, it cannot have evolved for the purpose of producing an awareness of ultimate meaning. That would constitute a teleological assumption and it would beg the question, not resolve it. Rather, the change induced through the archetype of ultimate meaning must come about due to the evolutionary solution to a different kind of problem. This problem has an immediate, mechanical aspect, and a more global, conceptual aspect. The second provides the context for the first.

The global problem consists in the construction of a societally-modulated system of intelligent production and utilization; a societal mind, really. The societal mind is the only means powerful enough to control, modulate, and utilize the symbolic processing power of the human brain. A single person is a necessary but insufficient condition for getting the most out of their own brain. This requires a dynamic, symbolic cultural form.

The mechanical problem concerns how to forge a complex societal mind out of components operating solely on the basis of self-interest. The principle of self-interest, random variation, and natural selection are the cornerstones of evolutionary theory. Evolution works because organisms are constantly trying to fulfill themselves. They are always acting so as to satisfy their own interests. It is a powerful concept. However, it is a basic contention of the proposed perspective that the incredible power contained within the intelligence of human beings can only be fully realized if humans are capable of operating under a non-self-centered 
perspective (see Wayment and Bauer, 2008). New motivational principles, e.g., humility, patience, beauty, peace, the good of all, must become operational.

These principles cannot arise, however, simply because of their moral strength. Rather, their advent must relate to real issues in the symbolic intelligence of human beings. In other words, these things do not come about because they are "good", or even because they are of great value. These benefits are apparent only after the fact. Rather, the evolution of symbolic consciousness must be driven by factors intrinsic to symbolic consciousness.

\section{Further directions}

This paper began by showing that the core concern in understanding the origin of religion is the need to explain the origin of the conception of a higher power. However, humans' symbolic computational capabilities are so great they are capable of modeling anythinganything real, anything imagined. Hence there is no actual problem with possessing a conception of a higher power. Literally, everyone has one. The question concerning the origin of a higher power then becomes a question of how the concept of a higher power, a mere image, becomes an ultimate concern, something of personal value.

My position is that an ultimate concern can be recognized as having a particular organization which I referred to above as the archetype of ultimate meaning. It consists of two main components. The first is a three-part ontology of ultimate power and meaning within the world, the other and the individual. The second component is a dual praxis of engagement with the ultimate concern (Doner, 2012). One form of this engagement, the exoteric path, seeks to realize the ultimate concern within the structure and nature of society; the other form, the esoteric path, seeks to realize ultimate meaning within the direct, all-encompassing experience of the individual. 
In general, a higher power moves beyond the imaginary and begins to become an ultimate concern, as the person begins to regard it as such. That is, they begin to see it as possessing deep relevance to their understanding of their world, their society, and themselves. It gains in significance as the person participates in actions expressing its ultimate meaning. These actions affirm the ultimate meaning of the higher power not only intellectually, but of even greater importance, ultimate meaning becomes embodied within the person's visceral engagement with reality (Csordas , 2002).

The person now lives their life as the ongoing experience that a higher power is the core power and meaning within their world, within their society, and within themselves. And such a person's actions, whatever they may be, will seek to express ultimate meaning either through their symbol-based engagement with society (Rappaport, 1999), or through their symbol-based engagement with the higher power. Ideally, the first builds a society that is maximally healthy; the second builds persons that are willing to build a society that is maximally healthy.

\section{Synopsis}

1. Religious processing is equivalent to spiritual processing since both constitute the processing of ultimate meaning.

2. With respect to the origin of ultimate meaning, existing perspectives fail to define four critical aspects of the problem. These are:

a. They fail to detail the critical elements and dimensions of religious processing.

b. They fail to specify what issues are resolved by the emergence of religious processing.

c. They fail to define a unique system underlying the processing of ultimate meaning.

d. They fail to delineate the relation between individual and social functions in the evolution of the processing of ultimate meaning. 
3. A new perspective is sketched which does provide answers for these four issues.

a. The archetype defines an ontology of transcendent power in the world, in the Other, and in the individual; it defines a dual praxis of relation, exoteric and esoteric, to ultimate meaning.

b. The emergence of religion leverages against self-interest; this makes symbolic culture possible; this, in turn, stabilizes and actualizes full human intelligence.

c. The archetype is hypothesized to correlate with a differentiated neural system of activity within the larger network of normal experience.

d. For the individual, the esoteric path leads to the direct experience of the ultimate; the exoteric path works on the growth of society. For the society, it is educated and inspired by, and therefore reveres and supports, the esoteric; it is built by the exoteric, and therefore prides itself on and promotes the exoteric path.

\section{References}

Abelow, B. J. (2009). Religious behavior as a reflection of childhood corporeal punishment (pp. 89-105). In J. R. Feierman (Ed.), The biology of religious behavior. The evolutionary origins of faith and religion. Santa Barbara, CA: Praeger.

Atran, S. (2002). In God we trust. The evolutionary landscape of religion. Oxford: Oxford University Press.

Beauregard, M. (2012). Neuroimaging and spiritual practice. In L. J. Miller (Ed.), The Oxford handbook of psychology and spirituality (pp. 514-527). New York: Oxford University Press. 
Bellah, R. N. (2011). Religion in human evolution: From the Paleolithic to the Axial Age. Cambridge, MA: Harvard University Press.

Benson, P. L., Roehlkepartain, E. C., and Scales, P. C. (2012). Spirituality and positive youth development. In L. J. Miller (Ed.), The Oxford handbook of psychology and spirituality (pp. 468-485). New York: Oxford University Press.

Bourdieu, P. (1977). Outline of a theory of practice. Cambridge: Cambridge University Press.

Boyer, P. (2010). The fracture of an illusion. Gottingen, DE: Vandenhoeck \& Ruprecht.

Cassirer, E. (1944). An essay on man. New Haven, CT: Yale University Press.

Ciarrocchi, J. W. (2012). Positive psychology and spirituality: A virtue-informed approach to well-being. In L. J. Miller (Ed.), The Oxford handbook of psychology and spirituality (pp. 425-436). New York: Oxford University Press.

Csordas, T. J. (2002). Body/Meaning/Healing. New York: Palgrave Macmillan.

Demmrich, S. (2013). 'And then I simply tried it' - Rituals and developmental tasks in the context of adolescent beliefs in East Germany. Presented at the Biennial Conference of the International Association for the Psychology of Religion, August, 2013, Lausanne, Switzerland.

Doner, J. (2012). The nature and consequences of informational differences in exoteric versus esoteric spiritual practices. Advances in the study of information and religion, 2, 21-46.

Doner, J. (2013a). The power and meaning of symbolic consciousness. Presented at the Midwinter Conference of the Society for Theoretical and Philosophical Psychology, Div. 24 of APA, February, 2013, Austin, TX. 
Doner, J. (2013b). Religion, science, and the archetype of ultimate meaning. Presented at the Mid-Year Conference of the Society for the Psychology of Religion and Spirituality, Div. 36 of APA, March, 2013, Columbia, MD.

Dumitriu, P. (1982). To the unknown God. London: Collins.

Durkheim, E. (1912/1995). The elementary forms of religious life. New York: The Free Press.

Eliade, M. (1959). The myth of the eternal return: Or, cosmos and history. New York: Harper Torchbooks.

Feierman, J. R. (Ed.), (2009). The biology of religious behavior. The evolutionary origins of faith and religion. Santa Barbara: Praeger.

Fowler, J. W. (1981). Stages of faith. The psychology of human development and the quest for meaning. New York: HarperCollins.

Freud, S. (1961). The future of an illusion. New York: W. W. Norton \& Company.

Geertz, C. (1973). The interpretation of cultures. New York: Basic Books.

Hume, D. (1779/1989). Dialogues concerning natural religion. Buffalo, NY: Prometheus Books.

James, W. (1902/1985). The varieties of religious experience. London: Penguin Books.

Jung, C. G. (1938). Psychology and religion. New Haven, CT: Yale University Press.

Lawson, E. T. and McCauley, R. N. (1990). Rethinking religion. Connecting cognition and culture. Cambridge: Cambridge University Press.

Lewis-Williams, D. (2010). Conceiving God: The cognitive origin and evolution of religion. London: Thames \& Hudson.

McNamara, P. (2009). The neuroscience of religious experience. Cambridge: Cambridge University Press.

Newberg, A. B. (2010). Principles of neurotheology. Surrey, UK: Ashgate Publishing. 
Newberg, A. B. (2012). Transformation of brain structure and spiritual experience. In L. J. Miller (Ed.), The Oxford handbook of psychology and spirituality (pp. 489-499). New York: Oxford University Press.

Newberg, A. and Waldman, M. R. (2009). How God changes your brain. New York: Ballantine Books.

Otto, R. (1923). The idea of the holy. Oxford: Oxford University Press.

Paloutzian, R. F. \& Park, C. L. (Eds.) (2005). Handbook of the psychology of religion and spirituality. New York: The Guilford Press.

Pals, D. L. (1996). Seven theories of religion. Oxford: Oxford University Press.

Park, C. L. and Slattery, J. M. (2012). Spirituality, emotions, and physical health. In L. J. Miller (Ed.), The Oxford handbook of psychology and spirituality (pp. 379-387). New York: Oxford University Press.

Petrician, R. and Burris, C. T. (2012), Am I the stone? Overattribution of agency and religious orientation. Psychology of Religion and Spirituality, 4(4), 312-323.

Rappaport, R. A. (1999). Ritual and religion in the making of humanity. Cambridge: Cambridge University Press.

Reynolds, V. and Tanner, R. (1983/1995). The social ecology of religion. Oxford: Oxford University Press.

Riesebrodt, M. (2010). The promise of salvation: A theory of religion. Translated by S. Rendall. Chicago: University of Chicago Press.

Saroglou, V. (2013). Conclusion: Understanding religion and irreligion. In V. Sarolgou (Ed.), Religion, personality, and social behavior (pp. 361-391). London: Psychology Press. 
Taves, A. (2009). Religious experience reconsidered: A building block approach to the study of religion and other special things. Princeton, NJ: Princeton University Press.

Tillich, P. (1957). The dynamics of faith. New York: Harper \& Row.

Tweed, T. A. (2006). Crossing and dwelling; A theory of religion. Cambridge, MA: Harvard University Press.

Watts, F. and Williams, M. (1988). The psychology of religious knowing. Cambridge: Cambridge University Press.

Wayment, H. A. and Bauer, J. J. (Eds.) (2008). Transcending self-interest. Psychological explorations of the quiet ego. Washington, DC: American Psychological Association.

Weber, M. (1956). The sociology of religion $4^{\text {th }}$ edition. Boston: Beacon Press.

\section{Biographical Sketch}

Jonathan Doner is a research and consulting psychologist with a Ph.D. from Vanderbilt University. He has presented and published papers on the origin of intelligence, the nature and structure of spiritual and religious pursuits, the quantitative structure of visual perception, and the relation between Aikido and leadership. Dr. Doner is also a digital artist, having exhibited in various galleries in the eastern United States. 